\title{
O FASCISMO, ONTEM E HOJE: DENÚNCIAS E RESISTÊNCIAS
}

\section{THE FASCISM, YESTERDAY AND TODAY: COMPLAINTS AND RESISTANCES}

\author{
EL FASCISMO, AYER Y HOY: QUEJAS Y RESISTENCIAS \\ DOI: http://dx.doi.org/10.9771/gmed.v11i2.34109 \\ Maria de Fátima Rodrigues Pereira ${ }^{1}$
}

A Germinal dedica este número ao fascismo. Tema difícil, doloroso. Em nós estão as memórias de nossos avós, pais, tios, tias, irmãos mais velhos. Lembram-nos da fome, do frio, do medo, da guerra, da violência, da morte, da ausência da liberdade de expressão, de ir e vir. Sim, o medo, incrustado profundamente, pela prepotência dos poderosos, também amedrontados, na vida de todos. Amparam-nos, as lições de nossos professores, a literatura de formação: O Diário de Anne Frank, Condição Humana, Eichman em Jesusalém de Hannad Arendt, Educação e Emancipação de Teodor Adorno, Dialética do Esclarecimento de Adorno e Horkheimer, entre outros. Também, a convicção crítica de que a história não acabou como anunciou, em 1989, Francis Fukayma, na sua obra o Fim da História. E, novamente, é necessário considerálo, porque há um flerte, aproximações, das políticas atuais com práticas nazi - fascistas, o que nos convoca ao esclarecimento, ao combate, à sua superação. Esta edição, insere-se, no esforço para vermos em nós mesmos e nas lutas contra a barbárie de ontem e de hoje.

Iasi, nos lembra, na Apresentação² que faz à obra de Leandro Konder- Introdução ao Fascismo.3 -, quando perscruta o objetivo do autor, que além de polemizar com as obras já produzidas sobre o fascismo, Konder teria o objetivo de alertar o leitor que existe uma universalidade no fascismo que ultrapassa suas manifestações particulares tal como se objetivaram na Itália e na Alemanha no contexto histórico da Segunda Guerra Mundial” (IASI, 2009, p.11-12). E acrescenta Iasi: “Despido de suas particularidades, o fascismo clássico revela fundamentos que podem encontrar novas formas de manifestação e aí reside seu verdadeiro perigo" (IASI, p. 2009, 12). Adianta, ainda, que Leandro Konder sustenta o debate com base no pressuposto de que o "fascismo é uma expressão política de direita que se liga ao capitalismo em sua fase monopolista na qual o Estado passa a ser essencial à produção e reprodução do capital” (IASI, 2009, p. 13). Aponta, em Konder as características do fascismo: “movimento político de conteúdo social conservador que se disfarça sob uma máscara 'modernizadora', guiado pela ideologia de um pragmatismo radical, servindo-se de mitos irracionalistas e conciliando-se com procedimentos racionalistas- formais do tipo manipulatório. O fascismo é um movimento chauvinista, antiliberal, antidemocrático, antissocialista, antioperário"” (IASI, 2009, p. 14). Para se instalar em uma país, aponta Iasi, conforme Leandro Konder, são precisas condições históricas: uma preparação reacionária que mine as potências potencialmente anti- fascistas e suas influências junto às 
massas “"pressupõe também as condições das chamadas sociedades de massas de consumo dirigido, bem como a existência nele de um certo nível de fusão do capital bancário com o capital industrial, isto é, o capital financeiro"” (IASI, 2009, p. 14).

O fascismo, surgiu na Itália e Alemanha logo após a Primeira Guerra Mundial, em um contexto histórico em que a possibilidade do socialismo era real, a Rússia vivia a revolução que levou ao poder os conselhos dos sovietes.

Benito Mussolini (o Duci), na Itália, criou, em 1921, o partido Partito Nazionale Fascista. Lhe atribuiu um símbolo- um feixe de varas, facio, palavra latina para designar as varas amarradas a um machado, usado pelos antigos lictores (littori) romanos, funcionários públicos que serviam os magistrados da justiça e os precediam nas suas diligências. "Os machados simbolizavam o poder do Estado de decapitar os inimigos da ordem pública. E as varas amarradas em redor do cabo constituíam um feixe que representava a unidade do povo em torno da sua liderança" (KONDER, p. 2009, 63).

Já na Alemanha, ainda em 1918, foi criado ao Partido Nacional - Socialista dos Trabalhadores Alemães, que usou a palavra Nazi com abreviatura. "Clara Ztkin, a veterana amiga de Rosa Luxemburg, preconizava, em 1923, uma mobilização geral de todo, o proletariado, ante o novo adversário, recomendando que se distinguisse claramente o fascismo de outras formas de repressão da direita" (KONDER, 2009, p.71).

Após a Primeira Guerra Mundial, 1914-1918, no período que precedeu a Segunda Guerra Mundial, tanto a Itália com a Alemanha viveram contextos sociais gravíssimos: o retorno de soldados desmobilizados nas frentes da guerra, sem trabalho, frequentemente se constituíam em bandos para militares que usavam de violência contra a população, a crise da hegemonia da burguesia e sua reorganização. Por outro lado, estava presente a possibilidade da revolução socialista, semelhante ao que acontecia na Rússia desde 1917, as lutas de uma classe trabalhadora militante, organizada em partidos. Na Alemanha a criação da República de Weimar, as conciliações e lutas entre os trabalhadores e estes com os partidos burgueses de direita.

A ascensão do fascismo na Itália na década de 1920 e do nazismo na Alemanha, na década de 30, com a queda do "Estado Social", em 1933, instituído pela Constituição de Weimar, contou com a complacência dos países vitoriosos na Primeira Guerra Mundial, preferiram "ignorar" e "tolerar" o que se passava nesses países, por temerem a revolução socialista, a política foi de contra- revolução.

Instituíram-se, então, regimes manipuladores das massas populares, amalgamadas numa falsa ideologia de união nacionalista de nós contra os outros. A propaganda, sistematicamente usada, acentuou a defesa da nação, a conciliação de classes, o segregacionismo racial, a superioridade da raça ariana, as heranças italianas da Roma Antiga, o uso da força bruta, o mito da nação, tão frágil e ao mesmo tempo tão poderoso de maneira que "o fascismo conseguiu recrutar adeptos em todas as classes sociais (inclusive nas classes que não teriam nada a lucrar com as suas políticas)" (KONDER, 2009, p.43).

As resistências foram duramente perseguidas, mortas, algumas poucas lograram fugir. $\mathrm{O}$ não reconhecimento do outro, do diferente, levou aos campos de concentração de Auschwitz - Birknau e outros, milhares de judeus, ao genocídio de ciganos, arménios, dos deficientes físicos e mentais. A banalidade do mal encontrou-se com razões cientificistas que justificaram os experimentos com humanos, 
Esses regimes ganharam apoio nas frações da burguesia hegemonizadas por aquelas ligadas ao capital financeiro que requeria um estado forte, repressivo, que favorecesse seus negócios, controlasse as classes trabalhadoras, hegemonizasse sua educação, a cultura. "Sabe-se, hoje, por exemplo, que no momento que Mussolini estava bastante deprimido com a derrota eleitoral que os fascistas italianos sofreram em novembro de 2019, ele recebeu substancial apoio de alguns grandes industriais, entre os quais, Max Bondi, do grupo Ilva, que era o principal grupo siderúrgico da Itália” (KONDER, 2009, p. 49). Já na Alemanha, "sabe-se, ainda de coisas mais sérias. Sabe-se que, em 26 de janeiro de 1932, Hitler fez no Clube da Indústria de Dusseldorf um discurso no qual antecipava seu programa econômico de governo, [...], calorosamente aplaudido por várias dezenas de grandes industriais e grandes banqueiros" (KONDER, 2009, p. 51).

O ensaio dos horrores, da banalidade do mal deu-se na Guerra Civil Espanhola (1936-1939), e, após a Segunda Guerra Mundial, (1939-1945), permaneceu na Espanha com o regime de Francisco Franco e em Portugal com Antônio de Oliveira Salazar com suas especificidades de serem países periféricos, assentes no apoio de forças conservadoras. No caso de Portugal, o apoio a tal regime vinha da burguesia terrateniente, seguida pela subfração industrial financeira e grande parte da hierarquia da Igreja Católica “incluindo não apenas a sua hierarquia, mas também as suas ramificações de intervenção social e política” (LOFF, 2010, p. 449) ${ }^{4}$, a exemplo de suas alas mais conservadoras como a Opus Dei. São conhecidas as orientações da Igreja nas políticas educacionais: "que a partir das reformas de 1936 se comprometia amplamente a Igreja na política educacional do Estado". Esses regimes não dispensavam o culto ao mito salvador da pátria, ao urgulhosamente sós, ao subterfúgio da propaganda como estratégia de manter as massas sob pressão e seu domínio, um sistema de educação unidimensional, omnipontente, apeado do debate das ideias e do caráter social das lutas entre capital e trabalho.

Hoje, quando o capital monopolista lá de trás, se expande e concentra exacerbadamente e o capital bancário fictício detém a hegemonia, vemos surgir políticas que flertam com o fascismo, mesmo em formações sociais com regimes democráticos burgueses, são práticas persecutórios àqueles que tem posições divergentes de quem está no poder, asfixia da crítica, a máquina de mídias de autopropaganda e de fake news, de desqualificação de quem se opõe, um ranço de fundamentalismo ignorante, anti -ciência, anti filosofia, anti-arte. No Brasil manifesta-se, em entre outras políticas, na escola sem partido, no não diálogo com as classes trabalhadoras, na sua desorganização para submetê-las, na perda de direitos dos trabalhadores, dos estudantes, das classes artísticas e culturais, as escolas militarizadas, o personalismo na política, o culto ao mito, no lawfare, na crise que abrange o sistema de justiça, no ataque a jornalista e imprensa, à $\mathrm{OAB}$, na narco política de segurança tão em evidência na cidade do Rio de Janeiro que todas as semanas nos lembra do genocídio dos pobres e negros e que nos traz sofrimento porque naqueles que sucumbem pela mão das forças autorizadas ou não, morre a humanidade de todos nós.

O tema - fascismo tem ocupado destacados cientistas políticos. Boron ${ }^{5}$ entende que o fascismo “é uma forma excepcional do Estado capitalista, com características absolutamente únicas e irrepetíveis, que irrompeu quando seu modo ideal de dominação, a democracia burguesa, enfrentou uma gravíssima crise no período entre a Primeira e a Segunda Guerra mundiais. Por isso dizemos que é uma "categoria histórica" e 
que já não pode ser reproduzida porque as condições que tornaram possível seu surgimento desapareceram para sempre" (BORON, 2019).

No Brasil, "Intelectuais e dirigentes políticos socialistas e progressistas têm afirmado que não se deve caracterizar o Governo Bolsonaro e o movimento que o apoia como fascistas ou neofascistas" (BOITO, 2019) ${ }^{6}$. Todavia, "Se no fascismo clássico, o grande capital nacional, diante da crise dos partidos políticos que tradicionalmente o representavam, confiscou o movimento pequeno-burguês, [...]; no neofascismo brasileiro, foi o capital internacional que, tendo em vista a crise do seu tradicional representante no Brasil, o PSDB, [...] e segmentos da grande burguesia brasileira [...] consolidou seu domínio na equipe governamental" (BOITO, 2019).

Há, entretanto, em alguns estudiosos do fascismo a convergência de que o fascismo é face do imperialismo, uma universalidade, daí sua permanência, sua insistência em existir nas suas especificidades. Erradicá-lo pressupõe além das resistências, submetê-lo e superá-lo.

Nesta edição dedicada ao passado e ao presente de uma face do modo de ser do imperialismo, o fascismo, comparecem autores que submeteram suas produções a Germinal, fazem denúncias e apontam resistências, propostas para a sua superação.

Da seção debate fazem parte quatro textos: André Francisco Brandão, autor de Crítica Lukacsiana ao Fascismo, apresenta em seu artigo sistematização da crítica de Lukács ao fascismo. O autor considera o fascismo "Forma regressiva oriunda da crise das sociedades burguesas maduras", que, "o movimento fascista constitui-se como uma alternativa política irracionalista, retrógrada, anti-humanista e aristocrática que é veiculada pela burguesia como válvula de escape para garantir a continuidade do sociomatabolismo capitalista" e que "Seu combate depende de um movimento que faça uma contraposição às suas características estruturais". O texto de Ricardo Gonçalves Severo, Rodrigo Duque Estrada, Sérgio Botton Barcellos intitulado Entre governos autoritários e aspirações fascistas na atualidade: o contexto internacional ao Brasil, expressa que o fascismo prende-se à "ação de grupos neoliberais, neoconservadores, a nova classe média profissional e populistas autoritários" e analisa "as possíveis relações entre os fascistas históricos e a extrema-direita que atuam em coalizão em diversos países no mundo". O artigo de Anita Helena Schlesener, Gilson Mezzaroba e Tatiani Garcia de Almeida- Reflexões sobre o fascismo e a violência no Brasil: a situação das classes trabalhadoras no momento de crise orgânica do capital- apresenta reflexão sobre a "ascensão de movimentos reacionários que retomam símbolos fascistas e nazistas e como estas ideologias se apresentam no Brasil, nas várias formas que assume a violência urbana e rural", considera "atual fase da luta de classes, [...], enquanto parte de uma política conservadora e repressiva num momento de grave crise financeira, que se estendeu dos centros capitalistas para a periferia, acompanhando as vias de internacionalização do capitalismo". Apresenta "esboço das raízes clássicas do fascismo para explicitar suas formas no atual momento histórico". Gianni Fresu no artigo- Civilização ocidental, ideologia colonial e fascismo, considera que "o fascismo resulta da opressão da liberdade individual a fim de intensificar a exploração e a expropriação do trabalho para a acumulação intensiva do capital [...] seu reaparecimento no momento de crise orgânica do capitalismo como um recurso de intensificação da exploração dos trabalhadores". 
Compõem a seção artigos 17 manuscritos agrupados em três núcleos: fazem parte do primeiro, dedicado a questões teóricas de resistências, enfrentamento a abordagens do conhecimento e desenvolvimento humano burguesas, os textos de Márcia Morschbacher, Décio Azevedo Marques Saes, Ricardo Eleutério dos Anjos, Juliane Cristina Zocoler, Júlio Ribeiro Soares, Gessica Fabiely Fonseca, João Victor da Silva Faustino, Samyr Damasceno Bonifá, Guilherme Torres Corrêa, Ana Lúcia Soares da Conceição Araújo. Este conjunto de textos faz contribuições à contraposição das estruturas onde se assenta o fascismo. Compõem o segundo núcleo, dedicado à denúncia das políticas neoliberais e seus impactos nas esferas da educação, trabalho e condições de vida do imigrante, os artigos de Gabriel Teles, Saulo Rodrigues Carvalho, Rachel Araujo de Matos, Adriana Alves da Silva, Gleiciana Noronha Guedes, Liara Aparecida da Costa Fiusa, Edson do Espírito Santo Filho, Vânia Pereira Moraes Lopes, Jacob Alfredo Iora, Fábio Araujo de Souza, Janeisi Lima Meira, Robson André Barata Medeiros, Janaina Gulart Oliveira Queiroz, Célia Regina Vendramini. O terceiro núcleo é composto por textos propositivos no sentido da superação das estruturas do fascismo, integram-no os artigos de Anita Leocádia Prestes, Wanderson Pereira Lima, Wanderson Pereira Lima, Iziane Silvestre Nobre Silvestre Nobre.

A entrevista é de Anita Leocádia Benário Prestes ${ }^{7}$, respondeu a um roteiro de perguntas elaborado por Gilcilene de Oliveira Damasceno Barão e Maria de Fátima Rodrigues Pereira. Em suas respostas Anita Prestes define pressupostos do fascismo, diferencia regimes autoritários dos fascistas e aponta quanto sua família foi vítima do fascismo.

Dois textos integram a seção clássicos: O fascismo e a sua política ${ }^{8}$ de Antônio Gramsci e La trayectoria del irracionalismo desde Schelling hasta Hitler de Georg Lukács. O primeiro integra a obra intitulada Escritos Políticos, vol. IV, produzida pelo autor e revolucionário sardo, na Itália de 1926, portanto, no calor da ascensão do fascimo. O segundo iniciado por seu autor durante a Segunda Guerra Mundial, foi terminado em 1952, em um contexto de constituição do Estado de Bem Estar Social e profundas mudanças na União Soviética, é o epílogo de uma extensão e rigorosa obra intitulada El Asalto a la Razon. La trayectoria del irracionalismo desde Schelling hasta Hitler. Ao longo da obra, Lukács apresenta seu estudo sobre a filosofía irracionalista, seus autores e contribuições ao fascismo, no Epílogo o autor reporta-se às mudanças do irracionalismo do pós Guerra.

Na secão resenhas, Raick de Jesus Souza traz ao leitor a obra de Rilton Ferreira Borges- Zola e as Percepcoes do Tempo: Naturalismo e História em Germinal- . Souza diz ao leitor como “ Emile Zola representa a experiência do tempo em Germinal (1885), tendo como pano de fundo as percepções de mudança do tempo, causadas, sobretudo, pela Segunda Revolução Industrial na Europa durante a segunda metade do século XIX”. A resenha, ora publicada, cumpre o desiderato de instigar o leitor a conhecer a obra de Rilton Ferreira Borges.

Agradecemos a todos (as) os (as) autores (as) pela decisão em publicarem pela Germinal. Também a Izaias Costa Filho pelo trabalho exaustivo de digitalizar os dois textos clássicos e prepará-los para publicação nesta edição.

Germinal, ao trazer o tema do fascismo contribui ao debate já instalado, cumpre, assim, mais uma vez, com esta edição, o compromisso assumido no seu projeto editorial, orientado pelo pressuposto que "é 
certo que a arma da crítica não pode substituir a crítica das armas, que o poder material tem de ser derrubado pelo poder material, mas, a teoria converte-se em força material quando penetra nas massas.

Boas leituras!

\section{Notas:}

${ }^{1}$ Doutora em Educação pela Unicamp. Professora do PPGED da Universidade Tuiuti do Paraná. ORCID: https://orcid.org/00000002-8511-2313 E-mail maria.pereira@utp.br

2 IASI, Mauro Luis. Nosso Guia na Floresta de Papel: O artífice da palavra clara. In: KONDER, Leandro. Introdução ao Fascismo. São Paulo: Expressão Popular, 2009.

${ }^{3}$ KONDER, Leandro. Introdução ao Fascismo. São Paulo: Expressão Popular, 2009.

444 LOFF, Manuel. Salazarismo e Franquismo: projecto, adaptação e história. In: Revista de História das Ideias. Ibéria. Vol. 31, 2010. p. 449 - 498 . https://digitalis-dsp.uc.pt/bitstream/10316.2/41518/1/Salazarismo e Franquismo.pdf. Consulta em 20/10/2019.

${ }^{5}$ Boron, Atílio A. Caracterizar o governo Jair Bolsonaro como "fascista" é um erro. In: https://www.brasildefato.com.br/2019/01/02/artigoor-caracterizar-o-governo-de-jair-bolsonaro-como-fascista-e-um-erro-grave/. Consulta em 20/10/2019.

${ }^{6}$ BOITO, Armando. A Terra é Redonda e o Governo Bolsonaro é Fascista. In https://www.brasil247.com/blog/a-terra-e-redonda-e-ogoverno-bolsonaro-e-fascista. Consulta em 20/10/2019.

${ }^{7}$ Anita Leocádia Benário é professora da Universidade Federal do Rio de Janeiro, filha de Olga Benário Prestes e de Luís Carlos Prestes, presidente do Instituto Carlos Prestes. E-mal: Anita Leocadia Prestes (superig.com.br)

8 Gramsci, Antonio. Escritos Politicos. vol. IV. Lisboa: Seara Nova, 1978.

9 LUKÁCS, Georg. El Asalto a la Razon. La trayectoria del irracionalismo desde Schelling hasta Hitler. Segunda Edición. EDICIONES GRIJALBO, S. A. Barcelona-México, D. F. 1968. 